\title{
A New Non-stationary Hydrological Drought Index Encompassing Climate Indices and Modified Reservoir Index as Covariates
}

\section{Youxin Wang}

China Three Gorges University

Tao Peng ( $\sim$ pengtao306@163.com )

China Three Gorges University

Qingxia Lin

China Three Gorges University

Vijay P Singh

Texas A\&M University

Xiaohua Dong

China Three Gorges University

Chen Chen

China Three Gorges University

Ji Liu

China Three Gorges University

Wenjuan Chang

China Three Gorges University

\section{Gaoxu Wang}

Nanjing Hydraulic Research Institute

\section{Research Article}

Keywords: Hydrological drought, Non-stationary Standardized Runoff Index, Modified reservoir index, GAMLSS, Hanjiang River basin

Posted Date: January 26th, 2022

DOI: https://doi.org/10.21203/rs.3.rs-1158084/v1

License: (c) (i) This work is licensed under a Creative Commons Attribution 4.0 International License.

Read Full License 
Version of Record: A version of this preprint was published at Water Resources Management on April 21st, 2022. See the published version at https://doi.org/10.1007/s11269-022-03151-y. 


\title{
A New Non-stationary Hydrological Drought Index Encompassing Climate Indices and Modified Reservoir Index as Covariates
}

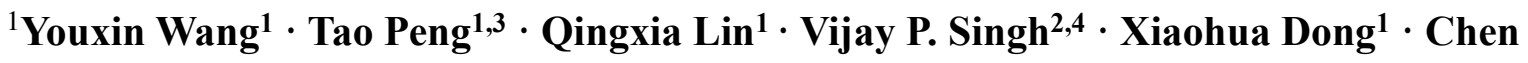 \\ Chen $^{1} \cdot$ Ji Liu ${ }^{1} \cdot$ Wenjuan Chang ${ }^{1}$ Gaoxu Wang ${ }^{3}$
}

\begin{abstract}
Due to accelerating climate variability and intensified anthropogenic activities, the hypothesis of stationarity of data series is no longer applicable, questioning the reliability of the traditional drought index. Thus, it is critical to develop a non-stationary hydrological drought index that takes into account the joint impacts of climate and anthropogenic changes in a drought assessment framework. In this study, using the Generalized Additive Model for Location, Scale and Shape (GAMLSS), a new non-stationary Standardized Runoff Index (NSRI) was developed combining

$\square$ Tao Peng

pengtao306@163.com

1 College of Hydraulic \& Environmental Engineering, and Engineering Research Center of Eco-environment in Three Gorges Reservoir Region, Ministry of Education, China Three Gorges University, Yichang, China

2 Department of Biological and Agricultural Engineering, and Zachry Department of Civil \& Environmental Engineering, Texas A\&M University, College Station, TX, USA

3 Key Laboratory of Flood \& Drought Disaster Defense, Ministry of Water Resources, Nanjing Hydraulic Research Institute, Nanjing, China

4 National Water \& Energy Center, UAE University, Al Ain, UAE
\end{abstract}


climate indices (CI) and modified reservoir index (MRI) as explanatory variables. This novel index was applied to the hydrological drought assessment of Hanjiang River basin (HRB) in China, and its reliability was assessed by comparing with the traditional Standardized Runoff Index (SRI). Results indicated that the optimal non-stationary model with CI and MRI as covariates performed better than did other models. Furthermore, NSRI was more robust in identifying extreme drought events and was more effective in the study region than the conventional SRI. In addition, based on the method of Breaks for Additive Seasonal and Trend (BFAST), it was found that there were two change points in 1981 and 2003 for NSRI series at four hydrological stations in the HRB, which indicated that hydrological drought in the basin had a prominent non-stationary behavior. Our findings may provide significant information for regional drought assessment and water resources management from a changing environment perspective.

Keywords Hydrological drought $\cdot$ Non-stationary Standardized Runoff Index $\cdot$ Modified reservoir index $\cdot$ GAMLSS $\cdot$ Hanjiang River basin

\section{Introduction}

As a complex and extensive natural disaster, drought has serious negative impacts on water resources, environment, agriculture, economy, and society (Mishra and Singh 2010). According to statistics, the global economic losses caused by drought disasters are as high as \$250-300 billion each year, far more than the losses caused by other meteorological disasters (Xu et al. 2021). In recent years, due to climate change and the intensification of human activities, the frequency and severity of drought disasters have been gradually increasing, and extreme drought events also occur from time to time, which have attracted extensive attention of the international community (Mittal 
et al. 2016; Zou et al. 2018; Tu et al. 2018; Williams et al. 2020). Drought is generally divided into meteorological drought, hydrological drought, agricultural drought, and socio-economic drought (Dracup et al. 1980; Wilhite and Glantz 1985). Among the different types of droughts, hydrological drought caused by insufficient surface and groundwater resources is considered to be one of the most important types of droughts (Shukla and Wood 2008).

The causes of hydrological drought are complex and are mainly affected by climate change and human activities (Van Loon et al. 2016; Ault 2020). For example, changes in precipitation and evaporation may exacerbate the intensity and frequency of global hydrological droughts in the 21 st century (Sheffield et al. 2012; Dai 2013). In addition, human activities such as land use/cover changes, agricultural irrigation, water extraction, and reservoir regulation have changed the hydrological cycle, resulting in variability in hydrological drought characteristics (Sheffield et al. 2012; Van Loon et al. 2016).

Due to the complexity and variability of drought, a drought index is usually used to describe and quantitatively evaluate drought characteristics (McKee et al. 1993; Mishra and Singh 2010; Vicente-Serrano et al. 2010). Many different drought index have been proposed, including Palmer Drought Intensity Index (Palmer 1965), Surface Water Supply Index (Shafer and Dezman 1982), Standardized Precipitation Index (SPI) (McKee et al. 1993), Standardized Precipitation Evapotranspiration Index (Vicente-serrano et al. 2010) and Standardized Runoff Index (SRI) (Shukla and Wood 2008), etc., and these have been widely used in various types of drought monitoring. SRI is widely used in hydrological drought monitoring (Shukla and Wood 2008) because of its simple calculation and comparability at different time scales. Moreover, the calculation of SRI is based on the hypothesis that the runoff time series is stationary. However, the 
assertion that the stationary hypothesis is no longer unreliable has been widely recognized due to the strong interference of climate change and human activities (Milly et al. 2008; Xiong et al. 2015). Therefore, it is necessary to establish non-stationary drought detection indexes considering the joint effects of climate variability and anthropogenic activities and investigate the evolution of nonstationary hydrological drought in a changing environment, which has important practical significance for monitoring and alleviating drought.

In recent years, researchers have begun to pay attention to the non-stationary analysis of hydrometeorological extreme events using the Generalized Additive Model for Location, Scale and Shape (GAMLSS), an effective tool for modeling time series under changing environment (Rigby and Stasinopoulos 2005). For example, Russo et al. (2013) proposed a non-stationary Standardized Precipitation Index (SnsPI) and indicated that SnsPI was more stable than the traditional SPI in modeling precipitation time series. Similarly, Wang et al. (2015) developed a time-based Standardized Precipitation Index (SPIt), which was more reliable than the traditional SPI. Bazrafshan et al. (2018) constructed a non-stationary Reconnaissance Drought Index (NRDI), which was superior to the conventional RDI in capturing drought characteristics. The abovementioned studies promoted the rapid development of non-stationary drought indices, but mainly aimed at meteorological drought. Moreover, most previous studies incorporated time or climate factors as explanatory variables to construct non-stationary models, and rarely considered the impact of human activities. A few researchers also attempted to incorporate reservoir index (López and Francés 2013; Su and Chen 2019) as a covariate of the non-stationary model to represent the impacts of anthropogenic factors on hydrometeorological variables. Results showed that the nonstationary model encompassing climate indices and reservoir index was more robust and effective 
than the non-stationary model considering only time or climate. However, the reservoir index adopted in previous studies was mostly used for non-stationary flood frequency analysis, and was seldom used in drought assessment. Thus, there is a need to develop a non-stationary drought index incorporating climate and reservoir indices as covariates for reliable hydrological drought analysis under changing environment.

The Hanjiang River basin (HRB) is one of the important commodity grain bases in China and is the water source of the middle route of the South-to-North Water Diversion Project. In recent years, due to the increasing impact of global climate change and human activities, the runoff in the HRB has decreased significantly, resulting in the increase of drought frequency and intensity. In recent 20 years, severe droughts occurred in the HRB in 2000, 2014, and 2016, which have exerted a significant negative impact on sustainable economic development and ecosystem health in the basin. Therefore, the objectives of this study are (1) to establish a non-stationary Standardized Runoff Index (NSRI) with climatic factors and modified reservoir index as covariables; (2) to assess the reliability of NSRI in comparison with the traditional SRI and historical drought events; and (3) to analyze the non-stationary characteristics of hydrological drought in the HRB from 1956 to 2020 based on NSRI. The study may provide a reference for river basin drought monitoring and assessment and sustainable utilization of water resources in a changing environment.

\section{Materials and Data}

\subsection{Study Area}

The Hanjiang River is the longest tributary of the Yangtze River (Fig. 1), which originates from Ningqiang County of Shaanxi Province and covers an area of $1.59 \times 10^{5} \mathrm{~km}^{2}$. The annual average 
temperature is $15-17^{\circ} \mathrm{C}$, and the annual average precipitation is $600-1300 \mathrm{~mm}$. Runoff in the basin is abundant, but its annual distribution is very uneven. From May to October, it accounts for about $75 \%$ of the whole year, with a great inter-annual variation. At present, more than 2900 reservoirs have been built in the $\mathrm{HRB}$, including about 40 large $\left(>0.1 \mathrm{~km}^{3}\right)$ reservoirs, with a total storage capacity of $48.6 \mathrm{~km}^{3}$. Table 1 shows the basic information of 5 controlling reservoirs $\left(>1 \mathrm{~km}^{3}\right)$ in the HRB.

\section{The position of Fig. 1}

Table 1 Controlling reservoirs $\left(>1 \mathrm{~km}^{3}\right)$ in the HRB

\begin{tabular}{cccccc}
\hline Reservoir & $\begin{array}{c}\text { Catchment } \\
\text { area }\left(10^{4} \mathrm{~km}^{2}\right)\end{array}$ & $\begin{array}{c}\text { Runoff } \\
\left(\mathrm{km}^{3} / \mathrm{yr}\right)\end{array}$ & $\begin{array}{c}\text { Total storage } \\
\text { capacity }\left(\mathrm{km}^{3}\right)\end{array}$ & $\begin{array}{c}\text { Utilizable storage } \\
\text { capacity } \\
\left(\mathrm{km}^{3}\right)\end{array}$ & Operation time \\
\hline Danjiangkou (DJK) & 9.52 & 39.48 & 31.95 & 16.12 & 1967 \\
Ankang (AK) & 3.86 & 19.2 & 2.58 & 1.67 & 1989 \\
Pankou (PK) & 0.90 & 4.55 & 2.34 & 1.12 & 2011 \\
Yahekou (YHK) & 0.30 & 1.08 & 1.32 & 0.81 & 1960 \\
Huanglongtan (HLT) & 1.11 & 6.02 & 1.16 & 0.47 & 1974 \\
\hline
\end{tabular}

\subsection{Data Collection}

The monthly runoff data of Ankang, Baihe, Huangjiagang, and Huangzhuang stations in the HRB from 1956 to 2020 were selected from the Hydrology Bureau of the Changjiang (Yangtze) Water Resources Commission (CWRC). Low-frequency climate indices which are physically related to runoff changes were selected as alternative explanatory variables of climate change factors. The climate indices, including southern Oscillation Index (SOI), Pacific Decadal Oscillation Index (PDO), Arctic Oscillation Index (AO), North Atlantic Oscillation Index (NAO), North Atlantic Multidecadal Oscillation Index (AMO), and North Pacific Oscillation Index (NPO), etc., were 
derived from the NOAA Climate Prediction Center (http://www.esrl.noaa.gov).

\section{Methodology}

\subsection{Standardized Runoff Index}

The Standardized Runoff Index (SRI) is a hydrologic drought monitoring index proposed by Shukla and Wood (2008). Its calculation method is similar to that of the Standardized Precipitation Index (SPI) (McKee et al. 1993). By calculating the cumulative probability of runoff data for a given period, the corresponding SRI value can be obtained through the normalization of probabilities of different distributions. The calculation principle is as follows:

It is generally considered that runoff series $x$ in a certain period satisfies the Gamma distribution (Sharma and Panu 2014). Then, its probability density function $f(x)$ is defined as follows:

$$
f(x)=\frac{1}{\gamma^{\beta} \Gamma(\beta)} x^{\beta-1} e^{-x / y}(x>0)
$$

where $\gamma$ and $\beta$ are the shape and scale parameters, respectively; $\gamma>0, \beta>0, \gamma, \beta$ can be calculated by maximum likelihood method; and $\Gamma(\beta)$ is the Gamma function. The cumulative probability $G(x)$ of runoff series $x$ can be formulated as:

$$
G(x)=\int_{0}^{x} f(x) d x
$$

The SRI value can be calculated approximately as follows:

$$
\begin{gathered}
S R I=S \frac{t-\left(c_{2} t+c_{1}\right) t+c_{0}}{\left[\left(d_{3} t+d_{2}\right) t+d_{1}\right] t+1.0} \\
t=\sqrt{-2 \ln (F)}
\end{gathered}
$$

When $F>0.5, S=1$; When $F \leq 0.5, S=-1$. Where $c_{0}=2.515517, c_{1}=0.802853, c_{2}=0.010328, d_{1}$ $=1.432788, d_{2}=0.189269, d_{3}=0.001308$. 


\subsection{Non-stationary Standardized Runoff Index}

\subsubsection{Climate Indices}

In this study, six large-scale low-frequency climate indices (SOI, PDO, AO, NAO, AMO, and NPO) were selected to represent climate anomalies. Kendall's rank correlation test (Hamed 2008) was applied at the confidence level of $95 \%$ to select significant climate indices which would be considered as explanatory variables for the GAMLSS model. To reduce monthly random variability of climate anomalies, a 12-month moving average of climate indices was carried out. Moreover, a time-lag correlation analysis was done between the runoff series of each station and the selected climate indices, and the lag period was set as 0-12 months to identify the significant climate indices related to runoff. The final explanatory variables of the GAMLSS model were selected from the candidate climate indices by the stepwise regression method.

\subsubsection{Modified Reservoir Index}

López and Francés (2013) proposed the reservoir index (RI) to represent the impacts of reservoirs on hydrological regimes, which is defined as follows:

$$
R I=\sum_{i=1}^{N}\left(\frac{A_{i}}{A_{T}}\right)\left(\frac{C_{i}}{C_{T}}\right)
$$

where $N$ is the number of reservoirs upstream of the hydrological station; $A_{i}$ is the catchment area of the reservoir $I ; A_{T}$ is the catchment area of the hydrological stations; $C_{i}$ is the total storage capacity of the reservoir $i$, and $C_{T}$ is the average runoff at the hydrological station. $R I$ is constant in a given period, regardless of the impact of reservoir regulation.

The effect of a reservoir on runoff regimes is closely related to annual runoff and the utilizable storage capacity of the reservoir. Therefore, we adopted the modified reservoir index (MRI) (Su 
and Chen 2019) to characterize the influence of reservoir on runoff, and its calculation formula is as follows:

$$
M R I=\sum_{i=1}^{N}\left(\frac{A_{i}}{A_{T}}\right)\left(\frac{C_{i}^{\prime}}{C_{t}}\right)
$$

where $C_{i}^{\prime}$ is the utilizable storage capacity of the reservoir $i$, and $C_{t}$ is the annual runoff at the hydrological station.

\subsubsection{Non-stationary Model Based on GAMLSS}

The generalized additive model for location, scale, and shape (GAMLSS) is a generalized regression model proposed by Rigby and Stasinopoulos (2005). Multiple explanatory variables can be added at the same time to describe the linear and nonlinear relationships between response variables and explanatory variables. In recent years, the GAMLSS model has been successfully applied to the analysis of time-varying characteristics of non-stationary hydrometeorological time series (López and Francés 2013; Jiang et al. 2015; Zhang et al. 2015). Therefore, using the GAMLSS framework, a non-stationary standardized runoff index was developed with climate indices and a modified reservoir index as explanatory variables.

The GAMLSS model assumes that independent observations $y_{i}(i=1,2, \ldots, n)$ have distribution function $f\left(y_{i} \mid \theta_{i}\right)$, where $\theta_{i}=\left(\theta_{i 1}, \theta_{i 2}, \ldots, \theta_{i p}\right)$ is a vector with $p$ distribution parameters representing the location, scale, and shape random variable characteristics. Let $g_{k}(\cdot)(k=1,2, \ldots, p)$ be a known monotone link function that is used to relate the distribution parameters to the explanatory variables. The semi-parametric additive formulation of the GAMLSS model used in this study is as follows:

$$
g_{k}\left(\theta_{k}\right)=\eta_{k}=X_{k} \beta_{k}+\sum_{j=1}^{J_{k}} Z_{j k} \gamma_{j k}
$$

where $\eta_{k}$ and $\theta_{k}$ are vectors of length $n ; X_{k}$ is a matrix of the explanatory variable of order $n \times J_{k}$; 
$\beta_{k}=\left(\beta_{1 k}, \beta_{2 k}, \ldots, \beta_{n k}\right)^{T}$ is the regression parameter vector of length $J_{k} ; Z_{j k}$ is a fixed known $n \times q_{j k}$ design matrix, and $\gamma_{j k}$ is a random variable vector of $q_{j k}$ dimension. $Z_{j k} \gamma_{j k}$ is the additive component representing the $j$ th random effect, and $q_{j k}$ represents the dimension of the random factor in the $j$ th random effect. The dependence can be linear or a smoothing term (López and Francés 2013). In this study, a cubic spline function was used to identify non-linear dependence when modeling the parameter distributions of explanatory variables.

Six different models were constructed to fit the monthly runoff series (Table 2). As shown in Table 2, the parameters of model 0 are stationary, while the parameters of the other five models are non-stationary.

Table 2 Description of six models in this study

\begin{tabular}{ccc}
\hline Model & Types of models & Description of parameters \\
\hline Model 0 & stationary & constant \\
Model 1 & non-stationary & linearly change with time \\
Model 2 & non-stationary & linearly change with CI \\
Model 3 & non-stationary & linearly change with MRI \\
Model 4 & non-stationary & linearly change with time and MRI \\
Model 5 & non-stationary & nonlinearly change with CI and MRI \\
\hline
\end{tabular}

The GAMLSS model parameters were estimated using the maximum likelihood estimator. Five commonly used two-parameter distributions were chosen as candidate distributions to fit the runoff series, namely Gumbel (GU), Gamma (GA), Weibull (WEI), Logistic (LO), and Lognormal (LOGNO). The Akaike Information Criterion (AIC) (Akaike 1974) was adopted to optimize the non-stationary model with the best fitting effect. The smaller the criterion value is, the higher the fitting accuracy of the model is. The rationality of the model was evaluated by the Filliben coefficient (Filliben 1975), the residuals, and the worm plot. All calculations in this study were performed using the R-based GAMLSS package (Rigby and Stasinopoulos 2005). 


\subsection{Identification of Hydrological Drought Characteristics}

Run theory (Yevjevich 1967) was employed to identify hydrological drought events and parameters (duration, severity, peak, etc.). A drought event is defined as the period during which a drought indicator value remains below a given threshold level (McKee et al. 1993). Drought duration is the persistent period between the initiation time and the termination time of a drought event. Drought severity and peak indicate the cumulative and maximum deficiency of drought indicators during the corresponding drought duration, respectively. In this study, three threshold levels $\left(X_{0}, X_{1}\right.$, and $X_{2}$ ) were selected to identify a drought event in a period, with values of $0,-0.5$, and -1.0 , respectively. Specifically, a drought event can be considered a period when the drought index (SRI, NSRI) values are between -0.5 and -1.0 or less than -1.0 . For the convenience of calculation, drought severity and peak were treated as positive values. In general, the calculation steps of NSRI are similar to those of SRI, except that NSRI is based on non-stationary distribution with varying parameters.

The categorization standard of SRI and NSRI are given in Table 3.

Table 3 Drought classification criteria based on SRI and NSRI

\begin{tabular}{ccc}
\hline Level & Index value (IV) & Drought grade \\
\hline 0 & IV $\geq-0.5$ & No drought \\
1 & $-1.0<\mathrm{IV}<-0.5$ & Mild drought \\
2 & $-1.5<\mathrm{IV}<-1.0$ & Moderate drought \\
3 & $-2.0<\mathrm{IV}<-1.5$ & Severe drought \\
4 & $\mathrm{IV} \leq-2.0$ & Extreme drought \\
\hline
\end{tabular}

\subsection{Breaks for Additive Seasonal and Trend (BFAST)}

Breaks for Additive Seasonal and Trend (BFAST) method is a time series decomposition model, 
which is widely used to detect long-term trend and abrupt change in time series (Verbesselt et al. 2010; Watts et al. 2014). The model decomposes the time series into trend, seasonality, and residual through iteration algorithm. The general form of the model is as follows:

$$
Y_{t}=T_{t}+S_{t}+e_{t}(t=1, \mathrm{~L}, n)
$$

where $Y_{t}$ is the observation data at time $t ; T_{t}$ and $S_{t}$ are the long-term trend component and seasonal (periodic) component, respectively; and $e_{t}$ is the residual component, which is the remaining part of the time series except the trend component and seasonal component.

It is assumed that the trend component $T_{t}$ has $m$ breakpoints, and the occurrence time of each breakpoint is $\tau_{1}, \ldots, \tau_{m}$, the linear model of $T_{t}$ between $\tau_{i-1}$ and $\tau_{i}$ can be expressed as:

$$
T_{t}=\alpha_{i}+\beta_{i} t\left(\tau_{i-1}<t \leq \tau_{i}\right)
$$

where $i$ is the position of the breakpoint, $i=1, \ldots, m ; \alpha_{i}$ and $\beta_{i}$ are the intercept and slope of the linear model on both sides of the breakpoint, respectively; and $\tau_{0}=0, \tau_{m+1}=n$.

Similarly, we assume that there are $p$ breakpoints in the seasonal component $S_{t}$, the occurrence time of each breakpoint is $\tau_{1}, \ldots, \tau_{p}$, then the periodic model of $S_{t}$ between $\tau_{j-1}$ and $\tau_{j}$ can be written as:

$$
S_{t}=\sum_{k=1}^{K} \alpha_{j, k} \sin \left(\frac{2 \pi k t}{f}+\delta_{j, k}\right)
$$

where $j$ is the position of the breakpoint, $j=1, \ldots, p ; \alpha_{j, k}$ and $\delta_{j, k}$ are the amplitude and phase, respectively; $f$ represents the frequency; and $k$ is the number of harmonic components in a periodic model.

\subsection{Cross Wavelet Transform}

The cross wavelet transform (XWT) is a signal analysis method that combines wavelet transform and cross-spectrum analysis. It can effectively investigate the interrelationship between two time 
series in both time and frequency. The detailed calculation procedures can be found in previous studies (Torrence and Compo 1998; Grinsted et al. 2004). In this study, the XWT method was employed to reveal the response of non-stationary hydrological drought to climate and anthropogenic factors.

\section{Results and Discussion}

\subsection{Non-stationary Analysis of Runoff Series}

The unit root test method (Cochrane 1991) was used to analyze the non-stationarity characteristics of the annual runoff series for four hydrological stations in the HRB from 1956 to 2020. As can be seen from Table 4, the $\mathrm{P}$ values of the four hydrological stations were all greater than 0.05 , indicating that the annual runoff series were non-stationary.

Table 4 Results of unit root test of annual runoff series at four hydrological stations in the HRB

\begin{tabular}{ccccc}
\hline Hydrologic station & t-statistic & 5\% level & P-value & Conclusion \\
\hline Ankang & -1.073 & -1.941 & 0.257 & Non-stationary \\
Baihe & -1.030 & -1.941 & 0.273 & Non-stationary \\
Huangjiagang & -1.133 & -1.941 & 0.234 & Non-stationary \\
Huangzhuang & -1.134 & -1.941 & 0.234 & Non-stationary \\
\hline
\end{tabular}

\subsection{Implementation of Non-stationary Models}

\subsubsection{Selection of Climate Indices}

Kendall rank correlation test at 5\% significance level was used to analyze the key climate indices affecting monthly runoff series at Huangzhuang station. As shown in Table 5, the climate indices significantly correlated with runoff series were distinct in different months, and the lag time was also different. Specifically, NPO was significantly correlated with monthly runoff series from 1956 to 2020 at Huangzhuang station. For SOI, there was a strong correlation between SOI and monthly 
runoff series in all months except from September to November. However, no significant correlation was observed between PDO, AO, NAO, and monthly runoff series at Huangzhuang station. Similar results were obtained at other hydrological stations. It is indicated that NPO is the dominant climate change factor of monthly runoff change in the HRB, followed by SOI and AMO.

Table 5 Selection of significant climate indices for the optimal non-stationary models at Huangzhuang station

\begin{tabular}{cccc}
\hline Month & $\mathrm{CI}$ & Month & $\mathrm{CI}$ \\
\hline Jan & $\mathrm{SOI}_{1}, \mathrm{NPO}_{2}$ & $\mathrm{Jul}$ & $\mathrm{SOI}_{2}, \mathrm{AMO}_{2} \mathrm{NPO}_{4}$ \\
$\mathrm{Feb}$ & $\mathrm{SOI}_{2}, \mathrm{NPO}_{3}$ & $\mathrm{Aug}$ & $\mathrm{SOI}_{5}, \mathrm{AMO}_{2} \mathrm{NPO}_{4}$ \\
$\mathrm{Mar}$ & $\mathrm{SOI}_{3}, \mathrm{NPO}$ & $\mathrm{Sep}$ & $\mathrm{AMO}, \mathrm{NPO}_{3}$ \\
$\mathrm{Apr}$ & $\mathrm{SOI}_{4}, \mathrm{AMO}, \mathrm{NPO}_{1}$ & $\mathrm{Oct}$ & $\mathrm{NPO}$ \\
May & $\mathrm{SOI}_{1}, \mathrm{AMO}, \mathrm{NPO}_{2}$ & $\mathrm{Nov}$ & $\mathrm{NPO}$ \\
Jun & $\mathrm{SOI}_{1}, \mathrm{AMO}, \mathrm{NPO}_{3}$ & $\mathrm{Dec}$ & $\mathrm{SOI}, \mathrm{NPO}_{1}$ \\
\hline
\end{tabular}

Note: The lag time of correlation between climate index and runoff series is indicated by a subscript, and the unit is a month.

\subsubsection{Changes in the Reservoir Index}

RI and MRI of four hydrological stations in the HRB were calculated using Eqs. (5) and (6), respectively. As can be seen from Fig. 2, RI showed stepwise changes over time, while MRI fluctuated irregularly after the reservoir operation. MRI at Ankang and Baihe stations showed an increasing trend after 1989 and reached 0.338 (Fig. 2a) and 0.118 (Fig. 2b) in 2002 and 1999, respectively, implying that it was greatly affected by the operation of AK Reservoir in 1989. Fig. 2c shows that Huangjiagang station is most significantly affected by large reservoirs among the four stations, and MRI increased sharply in 1967 and 2013, which is consistent with the operation time of the first and second phases of DJK Reservoir. The DJK Reservoir, the second-largest reservoir in the Yangtze River basin, was heightened from $162 \mathrm{~m}$ in 1967 to $176.6 \mathrm{~m}$ in 2013, the total storage capacity of the reservoir increased from $17.45 \mathrm{~km}^{3}$ to $31.95 \mathrm{~km}^{3}$ (Peng et al. 2020). 
Similarly, MRI at Huangzhuang station has experienced two dramatic increases due to the DJK Reservoir regulation. By comparison, MRI of Huangzhuang station was smaller than that of Huangjiagang station, which may be attributed to different distances between the two hydrological stations and DJK Reservoir.

\section{The position of Fig. 2}

\subsubsection{Optimization of GAMLSS Models}

Five probability distribution functions were used to fit the stationary model (model 0), and the bestfitting distribution was selected according to the principle of minimum AIC values. Table 6 summarizes the runoff fitting results at Huangzhuang station. As can be seen from Table 6, the Lognormal distribution had the best fitting performance overall, followed by the Gamma distribution, while the Weibull, Gumbel, and Logistic distributions had poor fits.

Table 6 AIC values of different probability distributions for runoff series at Huangzhuang station

\begin{tabular}{cccccc}
\hline \multirow{2}{*}{ Month } & \multicolumn{5}{c}{ Probability distribution } \\
\cline { 2 - 5 } & Gamma & Lognormal & Weibull & Gumbel & Logistic \\
\hline Jan & 826.08 & 823.83 & 836.28 & 871.29 & 834.20 \\
Feb & 828.62 & 826.51 & 838.13 & 872.72 & 837.18 \\
Mar & 830.79 & 828.75 & 839.60 & 873.02 & 840.04 \\
Apr & 830.83 & 828.69 & 839.26 & 870.03 & 840.91 \\
May & 830.50 & 829.43 & 837.11 & 863.97 & 839.85 \\
Jun & 830.94 & 830.56 & 836.52 & 861.85 & 839.40 \\
Jul & 823.66 & 821.97 & 832.31 & 862.03 & 831.67 \\
Aug & 819.20 & 818.77 & 825.90 & 851.48 & 825.94 \\
Sep & 814.29 & 813.36 & 822.60 & 848.57 & 820.36 \\
Oct & 816.83 & 814.54 & 828.63 & 863.47 & 822.68 \\
Nov & 820.11 & 817.61 & 831.88 & 868.18 & 826.70 \\
Dec & 835.83 & 833.48 & 846.90 & 882.86 & 843.33 \\
\hline
\end{tabular}

Table 7 shows the AIC values of the stationary model (model 0) and five non-stationary models (models 1-5) fitted by runoff data. Compared with other models, the AIC values of Model 5 are the smallest, indicating that Model 5 has the best fitting effect for the runoff series in the study 
area. It is worth noting that the non-stationary model presented more robust fitting effect than the stationary model due to incorporation of climate and anthropogenic factors as covariates. Additionally, Table 7 shows the explanatory variables of the optimal non-stationary model. The results exhibited that NPO was the climate index that had the most significant impact on the runoff series at Huangzhuang station. Moreover, MRI is the best choice for fitting the monthly runoff series, indicating that human activities have a significant impact on the non-stationarity of runoff.

Table 7 Summary of the AIC values of six different models, and selected explanatory variables of $\mu$ and $\sigma$ for the best model.

\begin{tabular}{|c|c|c|c|c|c|c|c|c|}
\hline \multirow{2}{*}{ Month } & \multicolumn{6}{|c|}{ AIC } & \multicolumn{2}{|c|}{ Explanatory variables } \\
\hline & Model 0 & Model 1 & Model 2 & Model 3 & Model 4 & Model 5 & $\mu$ & $\sigma$ \\
\hline Jan & 823.83 & 820.80 & 814.55 & 819.00 & 820.74 & 767.38 & NPO, MRI & NPO \\
\hline Feb & 826.51 & 823.64 & 817.60 & 821.64 & 823.44 & 766.74 & NPO, MRI & NPO \\
\hline Mar & 828.75 & 825.96 & 819.45 & 823.62 & 825.49 & 737.93 & NPO, MRI & NPO \\
\hline Apr & 828.69 & 825.91 & 815.82 & 823.09 & 825.01 & 737.23 & NPO, MRI & NPO \\
\hline May & 829.43 & 826.20 & 814.81 & 822.39 & 824.36 & 735.88 & NPO, MRI & NPO \\
\hline Jun & 830.56 & 827.66 & 815.58 & 822.50 & 824.48 & 739.65 & NPO, MRI & NPO \\
\hline Jul & 821.97 & 818.45 & 805.23 & 807.49 & 808.75 & 736.06 & NPO, MRI & NPO \\
\hline Aug & 818.77 & 815.61 & 806.23 & 798.17 & 797.05 & 716.37 & NPO, MRI & NPO \\
\hline Sep & 813.36 & 810.08 & 804.68 & 786.42 & 782.27 & 762.07 & NPO, MRI & NPO \\
\hline Oct & 814.54 & 811.85 & 807.81 & 770.13 & 760.29 & 669.54 & NPO, MRI & NPO \\
\hline Nov & 817.61 & 815.24 & 809.17 & 773.73 & 764.56 & 718.49 & NPO, MRI & NPO \\
\hline Dec & 833.48 & 830.27 & 824.19 & 790.08 & 783.88 & 735.69 & NPO, MRI & NPO \\
\hline
\end{tabular}

Table 8 summarizes residual moments for model 5 at Huangzhuang station. For a sample size of 64 , the Filliben coefficient at the $95 \%$ confidence level was about 0.981 . It can be seen from Table 8 that the Filliben coefficients were all greater than 0.981 , indicating insignificant deviations between the residuals of model 5 and normality. In addition, the mean and variance of model residuals were close to 0.00 and 1.0 , respectively, implying that the residuals of model 5 approximately followed the standard normal distribution. In other words, the fitting performance 
of the optimal non-stationary model was generally reliable.

Table 8 Residual moments for Model 5 at Huangzhuang station

\begin{tabular}{cccccc}
\hline Month & Mean & Variance & Skewness coefficient & Kurtosis coefficient & Filliben coefficient \\
\hline Jan & 0.000 & 1.016 & 0.111 & 2.959 & 0.989 \\
Feb & 0.000 & 1.016 & 0.104 & 2.908 & 0.988 \\
Mar & 0.000 & 1.016 & -0.229 & 2.759 & 0.993 \\
Apr & 0.001 & 1.016 & -0.295 & 2.999 & 0.990 \\
May & 0.001 & 1.016 & -0.255 & 3.271 & 0.989 \\
Jun & -0.001 & 1.016 & -0.429 & 3.206 & 0.985 \\
Jul & 0.000 & 1.016 & -0.090 & 3.332 & 0.987 \\
Aug & 0.000 & 1.016 & -0.207 & 3.544 & 0.985 \\
Sep & 0.000 & 1.014 & -0.277 & 2.494 & 0.988 \\
Oct & 0.000 & 1.010 & -0.306 & 3.535 & 0.985 \\
Nov & 0.000 & 1.016 & 0.044 & 3.188 & 0.992 \\
Dec & 0.000 & 1.016 & -0.056 & 3.229 & 0.991 \\
\hline
\end{tabular}

To further verify the reliability of the optimal non-stationary model, the normal Q-Q plot, the worm plot of residuals, and the quantile plot were analyzed. Due to space limitations, the runoff series of Huangzhuang station in December was taken as an example to demonstrate the normal QQ plot, residual worm plot, and the quantile plot of the optimal model (Fig. 3). It can be seen from Fig. 3 that the results of the normal Q-Q plot and the worm plot did not exhibit a significant departure from normality, implying that the runoff series was effectively fitted by the optimized model.

\section{The position of Fig. 3}

Additionally, five different quantiles (5th, 25th, 50th, 75th, and 95th) of six models were displayed for runoff series in December at Huangzhuang station from 1956 to 2020 (Fig. 4). As can be seen from Fig. 4, the quantile ranges from 5\% to 95\% covered almost all observed values of 
Model 5, suggesting that the distribution of observed values from the non-stationary Model 5 (Fig. 4f) was more reasonable than the other five models. Specifically, compared with Model 0 (Fig. 4a), the quantile plot of the non-stationary models (Fig. 4(b-f)) showed irregular fluctuations, which better described the non-linear changes of measured runoff data in the study area. Compared with the other four non-stationary models, the fluctuation range of Model 5 results was larger, which can more effectively characterize the extreme runoff behavior and significantly improve the model fitting ability.

\section{The position of Fig. 4}

\subsection{Applicability of NSRI}

The SRI and NSRI of Huangzhuang station at 12-month time scale from 1956 to 2020 were calculated. It can be seen from Fig. 5 that the temporal variations of SRI and NSRI from 1956 to 2020 were similar, suggesting that NSRI effectively identified the drought process. Historical records and previous studies (Jiang et al. 2021) show that the HRB suffered from severe drought events in 1966, 2000, 2014, and 2016. It was evident that the drought conditions identified by NSRI were more consistent with historical drought records. Moreover, the drought severity identified by NSRI was generally higher than that identified by SRI, indicating more severe drought conditions than of SRI. In this study, we selected the typical drought events in 2014 and 2016 to further evaluate the performance of NSRI and SRI. Notably, the two severe drought events can also be identified by NSRI and SRI, which have brought great damage to agricultural production, life, and ecosystem in the HRB. In 2014, approximately 5 million people in Hubei province suffered a severe drought, with a direct economic loss of nearly 2 billion yuan. Affected by low precipitation in 2016, 
a rare drought broke out in the northwestern part of Hubei, with over 230,000 people experiencing drinking water difficulties. Nevertheless, NSRI, with a lower value, exhibited more severe drought conditions than did SRI for the two typical drought events. It is obvious that the results of NSRI better reflected the actual drought conditions than those of SRI, which implied that NSRI was more reliable for drought evaluation under changing environment.

\section{The position of Fig. 5}

\subsection{Comparison of Results between SRI and NSRI}

Fig. 6 shows hydrological drought frequency based on SRI and NSRI at Huangzhuang station for different periods and different drought levels from 1956 to 2020. As can be seen from Fig. 6a, the frequency of mild drought based on SRI was higher than that based on NSRI in most periods. SRI and NSRI reached the highest mild drought frequencies of $35.14 \%$ and $25.83 \%$ respectively, which occurred during 1956-1959 and 1990-1999 respectively. For moderate drought events (Fig. 6b), the frequency identified by SRI was the highest during 2000-2009 (18.33\%), whereas the frequency identified by NSRI was the highest during 1990-1999 (16.67\%). Besides, as shown in Fig. 6c, the frequency of severe drought calculated by SRI and NSRI arrived their maximum values between 2010 and 2020 , with rates of $15.91 \%$ and $10.61 \%$, respectively. As can be seen for extreme drought events (Fig. 6d), the frequency based on NSRI was higher than that based on SRI during all periods except the period from 2000 to 2009. In particular, the frequency of extreme drought identified by NSRI reached $9.85 \%$ from 2010 to 2020 . It is worth noting that the frequency of light and medium drought based on SRI were slightly higher than those based on NSRI during the entire period, but the opposite results appeared for severe and extreme drought conditions. 


\section{The position of Fig. 6}

Drought properties, such as duration, severity, and peak, based on NSRI and SRI at Huangzhuang station from 1956 to 2020 were identified by run theory. As can be seen from Fig. 7, the mean and median values of drought duration and severity based on NSRI were generally lower than those based on SRI, while the mean and median values of drought peak were opposite. In addition, the variation range of drought features using NSRI was larger than that using SRI. These results indicated that drought duration identified by SRI was longer, but drought peak defined by NSRI was higher, which was consistent with the results of previous studies (Wang et al. 2020).

\section{The position of Fig. 7}

\subsection{Non-stationary Changes of Hydrological Drought}

Fig. 8 illustrates the detection results of NSRI at four hydrological stations in the HRB after iterative decomposition by the BFAST method. As can be seen from the figure, the trend showed that there were two breakpoints within the time series of NSRI. The abrupt change occurred in 1981 and 2003, respectively, which indicated that the hydrological drought in the HRB had a distinctly non-stationary change. Specifically, it showed a moderate decreasing trend of NSRI from December 1956 to January 1981, suggesting that the hydrological drought conditions in the study area had progressively intensified. Subsequently, NSRI values at Ankang, Baihe, Huangjiagang, and Huangzhuang stations increased precipitously in February 1981 and dropped sharply until September 2003, with average downward rates of $-0.148 / \mathrm{a},-0.141 / \mathrm{a},-0.096 / \mathrm{a}$, and $-0.078 / \mathrm{a}$ from February 1981 to September 2003, respectively, all exceeding 99.9\% confidence level. In other words, the study area witnessed an increasingly severe drought between February 1981 and 
September 2003. However, the NSRI values at the four hydrological stations increased sharply again in October 2003 and then showed an insignificant decreasing trend at Ankang and Baihe stations, and a significant downward trend at Huangjiagang and Huangzhuang stations above 99\% confidence level. On the whole, the hydrological regime of the HRB tended to be arid, and this trend became more obvious after 1981.

\section{The position of Fig. 8}

\subsection{Effects of Atmospheric Circulation and Reservoir Regulation on Hydrological Drought}

Studies have shown that non-stationary variability in hydrological drought is closely associated with large-scale atmospheric circulation patterns (Talaee et al 2014; Huang et al 2016; Ault et al. 2020). The abnormal atmospheric circulation caused by sea surface temperature has been widely regarded as a major driver of drought events ( $\mathrm{Li}$ et al 2015; Oñate-Valdivieso et al. 2020). Therefore, the key climate indices (including NPO, SOI, AMO, and PDO) were selected to further explore the linkage between atmospheric circulation anomalies and hydrological drought by cross-wavelet transform (XWT) analysis. Fig. 9 illustrates the cross-wavelet power spectrum between NSRI and NPO, SOI, AMO, and PDO. As shown in Fig. 9a, there was a significant negative correlation between NSRI and NPO, with cycles of 2-4 years from 1961 to 1970, 7-12 years during 1968-1990, and 5-6 years in 2007-2014, respectively. Fig. $9 \mathrm{~b}$ represents a strong negative correlation between NSRI and AMO with periodic signals of 2-4 years from 1964 to 1972, 7-11 years during 19681992, and 1-2 years in 2011-2016. Fig. 9c exhibits approximately positive correlations between NSRI and SOI, with cycles of 2-4 years and 1-2 years for the period 1964-1972 and 2010-2015, respectively. For PDO (Fig. 9d), the cycles were 3 years and 5-6 years during 1968-1970 and 2010- 
2014, respectively. In general, NPO had the most significant effect on hydrological drought in the HRB, followed by SOI and AMO, while PDO had a weak effect on drought. These results are confirmed by the results in Table 5. Therefore, the non-stationary hydrological drought index encompassing large-scale atmospheric circulation indices can effectively avoid the drawback of stationary hydrological drought index in the changing environment.

\section{The position of Fig. 9}

Human activities, such as agricultural irrigation, water abstraction, land-use change, reservoir regulation, and inter-basin water transfer, exert a profound influence on the hydrological cycle, which can then result in the spatio-temporal variability of hydrological drought (López-Moreno et al. 2009; Wen et al. 2011; Van Loon et al. 2016; Lin et al. 2017). Runoff regulation caused by reservoir operation strategies is known to be the key driver for hydrological alteration (Rangecroft et al. 2016). Reservoir regulation strategies reduce the hydrological drought duration and intensity by releasing stored water during the dry season (Wen et al. 2011; Rangecroft et al. 2016; Wu et al. 2018). However, the negative impacts of the reservoir on the downstream drought characteristics have been demonstrated by recent studies that reservoir regulation was responsible for the increase in drought severity downstream of the dam (López-Moreno et al. 2009; Wang et al. 2020). Flow regimes in the HRB are highly regulated by multiple reservoirs, especially large reservoirs (Fig. 1 and Table 1). Fig. 10 shows the cross-wavelet power spectrum between modified reservoir index MRI and NSRI at four hydrological stations using the XWT analysis. It can be seen from Fig. 10a that an anti-phase correlation with a 1-6 years periodic signal was detected at Ankang station during 1997-2006. However, Fig. 10b shows an in-phase correlation between MRI and NSRI with a 1-2 years period from 1998 to 2006 at Baihe station. MRI of Huangjiagang station (Fig. 10c) had two 
cycles with NSRI, which showed a negative correlation with 1-3 years and 5-7 years periodic signals during 2010-2017 and 2009-2014, respectively. There was a period with a negative signal of 1-2 years and 5-7 years during 2011-2017 and 2009-2014 at Huangzhuang station (Fig. 10d). On the whole, there was a significant correlation between MRI and NSRI, indicating that reservoir regulation was also an important driving factor of hydrological drought in the HRB. Hence, MRI can be considered as a key covariate of the GAMLSS-based non-stationary model to describe the nonlinear variability of streamflow in the basin.

\section{The position of Fig. 10}

\section{Conclusions}

In this study, we proposed a new non-stationary Standardized Runoff Index (NSRI) using the GAMLSS framework, which encompassed large-scale climate indices (CI) and modified reservoir index (MRI) as explanatory variables. The reliability of NSRI in the HRB was evaluated by comparing with the traditional standardized runoff index (SRI) and historical drought events. Then, the non-stationary evolution characteristics of hydrological drought in the HRB were analyzed. Our main findings can be summarized as follows.

(1) We observed that NPO was the dominant climate index and had a significant correlation with monthly runoff series. Moreover, the reservoir exerted a profound effect on the runoff change, especially in the middle-lower reach of the HRB under intensified regulation of the DJK Reservoir. Results demonstrate that the non-stationary model with CI and MRI as explanatory variables exhibits better performance than other models, and is more effective for modeling monthly runoff in terms of reflecting the impacts of climate and anthropogenic changes.

(2) It is found that NSRI is superior to SRI in reconstructing the historical drought records in the 
HRB, and is more reliable for drought assessment under non-stationary conditions. The significant difference between NSRI and SRI lies in the assessment results of extreme drought events, indicating that NSRI has a better ability to capture extreme values.

(3) Two breakpoints in 1981 and 2003 for NSRI series at four hydrological stations in the HRB were detected using the method of BFAST, implying that hydrological drought in the study area has experienced non-stationary changes.

Overall, the performance of NSRI is more robust than the traditional SRI for drought monitoring, which can better describe the non-stationary characteristics of runoff series and significantly improve the detection ability of hydrological drought in a changing environment. However, the driving mechanism of non-stationary variation in hydrological drought caused by large-scale climate anomalies and region-specific anthropogenic disturbances is extremely complex. Hence, more feasible climate indices and anthropogenic factors that may affect hydrological drought can be considered as external covariates of non-stationary hydrological drought in further studies, which can provide a valuable support for monitoring and mitigation of drought.

Authors Contributions Conceptualization: Y. Wang, T. Peng, X. Dong, C. Chen; Methodology: Y. Wang, T. Peng; Investigation: T. Peng, J. Liu, W. Chang, G. Wang; Original draft preparation: Y. Wang, T. Peng; Writing - review \& editing: Y. Wang, T. Peng, Q. Lin, VP. Singh; Supervision: T. Peng.

Funding This study was supported by the National Natural Science Foundation of China (52009065), the Natural Science Foundation of Hubei Province (2020CFB293), and the Yichang Natural Science Research Project (A213-004). 
Data Availability The data used to support this study are available through contacting the corresponding author.

\section{Declarations}

Ethical Approval Not applicable.

Consent to Participate The authors agree to participate in any survey or feedback task.

Consent to Publish The authors agree to provide manuscript for publication to the publisher of the journal.

Conflict of Interest The authors declare that they have no known competing interests.

\section{References}

Akaike H (1974) A new look at the statistical model identification. IEEE Trans Autom Control 19(6):716-723. https://doi.org/10.1109/TAC.1974.1100705

Ault $\mathrm{T}$ (2020) On the essentials of drought in a changing climate. Sci 368(6488):256-260. https://doi.org/10.1126/science.aaz5492

Bazrafshan J, Hejabi S (2018) A Non-stationary Reconnaissance Drought Index (NRDI) for drought monitoring in a changing climate. Water Resour Manage 32(8):2611-2624. https://doi.org/10.1007/s11269-018-1947-z

Cochrane, JH (1991) A critique of the application of unit root tests. J Econ Dynam Control 15(2):275-284. https://doi.org/10.1016/0165-1889(91)90013-Q

Dai AG (2013) Increasing drought under global warming in observations and models. Nat Clim Change 3(1):52-58. https://doi.org/10.1038/nclimate1633

Dracup J, Lee K, Paulson E (1980) On the definition of droughts. Water Resour Res 16(2):297-302. https://doi.org/10.1029/WR016i002p00297

Filliben JJ (1975) The probability plot correlation coefficient test for normality. Technometrics 17(1):111-117. https://doi.org/10.1080/00401706.1975.10489279

Grinsted A, Moore JC, Jevrejeva S (2004) Application of the cross wavelet transform and wavelet coherence to geophysical time series. Nonlin Process Geophys 11(5-6):561-566. https://doi.org/10.5194/npg-11-561-2004 
Hamed KH (2008) Trend detection in hydrologic data: the Mann-Kendall trend test under the scaling hypothesis. J Hydrol 349(3-4):350-363. https://doi.org/10.1016/j.jhydrol.2007.11.009

Huang SZ, Huang Q, Chang JX, Leng GY (2016) Linkages between hydrological drought, climate indices and human activities: a case study in the Columbia River basin. Int J Climatol 36(1):280-290. https://doi.org/10.1002/joc.4344

Jiang C, Xiong LH, Xu C-Y, Guo SL (2015) Bivariate frequency analysis of nonstationary low-flow series based on the time-varying copula. Hydrol Process 29(6):1521-1534. https://doi.org/10.1002/hyp.10288

Jiang WX, Wang LC, Zhang M, Yao R, Chen XX, Gui X, Sun J, Cao Q (2021) Analysis of drought events and their impacts on vegetation productivity based on the integrated surface drought index in the Hanjiang River Basin, China. Atmos Res 254:105536. https://doi.org/10.1016/j.atmosres.2021.105536

Li JZ, Wang YX, Li SF, Hu R (2015) A Nonstationary Standardized Precipitation Index incorporating climate indices as covariates. J Geophys Res Atmos 120(23):12082-12095. https://doi.org/10.1002/2015JD023920

Lin QX, Wu ZY, Singh V P, Sadeghi SHR, He H, Lu GH (2017) Correlation between hydrological drought, climatic factors, reservoir operation, and vegetation cover in the Xijiang basin, South China. J Hydro 549:512-524. http://dx.doi.org/10.1016/j.jhydrol.2017.04.020

López-Moreno JI, Vicente-Serrano SM, Beguería S, García-Ruiz JM, Portela MM, Almeida AB (2009) Dam effects on droughts magnitude and duration in a transboundary basin: The Lower River Tagus, Spain and Portugal. Water Resour Res 45: W02405. https://doi.org/10.1029/2008WR007198

López J, Francés F (2013) Non-stationary flood frequency analysis in continental Spanish rivers, using climate and reservoir indices as external covariates. Hydrol Earth Syst Sci 17(8):3189-3203. https://doi.org/10.5194/hess-17$3189-2013$

McKee TB, Doesken NJ, Kleist J (1993) The relationship of drought frequency and duration to time scales. Eighth Conference on Applied Climatology. American Meteorological Society, Anaheim, pp. 179-184. 
Milly PCD, Betancourt J, Falkenmark M, Hirsch RM, Kundzewicz ZW, Lettenmaier DP, Stouffer RJ (2008) Stationarity is dead: whither water management? Sci 319(5863):573-574. https://doi.org/10.1126/science.1151915

Mishra AK, Singh VP (2010) A review of drought concepts. J Hydrol 391(1-2):202-216. https://doi.org/10.1016 /j.jhydrol.2010.07.012

Mittal N, Bhave AG, Mishra A, Singh R (2016) Impact of human intervention and climate change on natural flow regime. Water Resour Manage 30(2):685-699. https://doi.org/10.1007/s11269-015-1185-6

Oñate-Valdivieso F, Uchuari V, Oñate-Paladines A (2020) Large-scale climate variability patterns and drought: a case of study in South-America. Water Resour Manage 34(6):2061-2079. https://doi.org/10.1007/s11269-020-02549W

Palmer WC (1965) Meteorological Drought. Research Paper No. 45. US Department of Commerce Weather Bureau, Washington DC.

Peng T, Tian H, Singh VP, Chen M, Liu J, Ma HB, Wang JB (2020) Quantitative assessment of drivers of sediment load reduction in the Yangtze River basin, China. J Hydrol 580:124242. https://doi.org/10.1016/j.jhydrol.2019.124242

Rangecroft S, Van Loon AF, Maureira H, Verbist K, Hannah DM (2016) Multi-method assessment of reservoir effects on hydrological droughts in an arid region. Earth Syst Dynam Discuss 1-32. https://doi.org/10.5194/esd-2016-57

Rigby RA, Stasinopoulos DM (2005) Generalized additive models for location scale and shape. Appl Stat 54(3):507554. https://doi.org/10.1111/j.1467-9876.2005.00510.x

Russo S, Dosio A, Sterl A, Barbosa P, Vogt J (2013) Projection of occurrence of extreme dry-wet years and seasons in Europe with stationary and nonstationary Standardized Precipitation Indices. J Geophys Res Atmos 118(14):7628-7639. https://doi.org/10.1002/jgrd.50571

Shafer BA, Dezman LE (1982) Development of a Surface Water Supply Index (SWSI) to assess the severity of drought conditions in snowpack runoff areas. In Proceedings of the (50th) 1982 Annual Western Snow Conference, pp. 
164-175 Fort Collins, CO: Colorado State University

Sharma TC, Panu US (2014) Modeling of hydrological drought durations and magnitudes: experiences on Canadian streamflows. J Hydrol Reg Stud 1:92-106. https://doi.org/10.1016/j.ejrh.2014.06.006

Sheffield J, Wood EF, Roderick ML (2012) Little change in global drought over the past 60 years. Nat 491(7424):435438. https://doi.org/10.1038/nature11575

Shukla S, Wood AW (2008) Use of a standardized runoff index for characterizing hydrologic drought. Geophys Res Lett 35(2). https://doi.org/10.1029/2007GL032487

Su CJ, Chen XH (2019) Assessing the effects of reservoirs on extreme flows using nonstationary flood frequency models with the modified reservoir index as a covariate. Adv Water Resour 124:29-40. https://doi.org/10.1016/j.advwatres.2018.12.004

Talaee P, Tabari H, Ardakani S (2014) Hydrological drought in the west of Iran and possible association with largescale atmospheric circulation patterns. Hydrol Process 28(3):764-773. https://doi.org/10.1002/hyp.9586

Torrence C, Compo GP (1998) A practical guide to wavelet analysis. Bull Am Meteorol Soc 79(1):61-78. https://doi.org/10.1175/1520-0477(1998)079<0061:APGTWA>2.0.CO;2

Tu XJ, Wu HO, Singh VP, Chen XH, Lin KR, Xie YT (2018) Multivariate design of socioeconomic drought and impact of water reservoirs. J Hydrol 566:192-204. https://doi.org/10.1016/j.jhydrol.2018.09.012

Van Loon AF, Gleeson T, Clark J, Dijk AV, Stahl K, Hannaford J, Baldassarre, GD, Teuling AJ, Tallaksen LM, Uijlenhoet R (2016) Drought in the Anthropocene. Nat Geosci 9(2):89-91. https://doi.org/10.1038/ngeo2646

Verbesselt J, Hyndman R, Zeileis A, Culvenor D (2010) Phenological change detection while accounting for abrupt and gradual trends in satellite image time series. Remote Sens Environ 114(12):2970-2980. https://doi.org/10.1016/j.rse.2010.08.003

Vicente-Serrano SM, Beguería S, López-Moreno JI (2010) A multiscalar drought index sensitive to global warming: the standardized precipitation evapotranspiration index. J Clim 23(7):1696-1718. 
https://doi.org/10.1175/2009JCLI2909.1

Wang YX, Duan LM, Liu TX, Li JZ, Feng P (2020) A non-stationary standardized streamflow index for hydrological drought using climate and human-induced indices as covariates. Sci Total Environ 699:134278-. https://doi.org/10.1016/j.scitotenv.2019.134278

Wang YX, Li JZ, Feng P, Hu R (2015) A time-dependent drought index for non-stationary precipitation series. Water Resour Manage 29(15):5631-5647. https://doi.org/10.1007/s11269-015-1138-0

Watts LM, Laffan SW (2014) Effectiveness of the BFAST algorithm for detecting vegetation response patterns in a semi-arid region. Remote Sens Environ 154:234-245. http://dx.doi.org/10.1016/j.rse.2014.08.023

Wen L, Rogers K, Ling J, Saintilan N (2011) The impacts of river regulation and water diversion on the hydrological drought characteristics in the lower Murrumbidgee River, Australia. J Hydrol 405(3-4):382-391. https://doi.org/10.1016/j.jhydrol.2011.05.037

Williams AP, Cook ER, Smerdon JE, Cook BI, Abatzoglou JT, Bolles K, Baek SH, Badger AM, Livneh B (2020) Large contribution from anthropogenic warming to an emerging North American megadrought. Sci 368(6488):314-318. https://doi.org/10.1126/science.aaz9600

Wilhite DA, Glantz MH (1985) Understanding the drought phenomenon: the role of definitions. Water Int 10(3):111120. https://doi.org/10.1080/02508068508686328

Wu JF, Liu ZY, Yao HX, Chen XH, Chen XW, Zheng YH, He YH (2018) Impacts of reservoir operations on multiscale correlations between hydrological drought and meteorological drought. J Hydrol 563:726-736. https://doi.org/10.1016/j.jhydrol.2018.06.053

Xiong LH, Du T, Xu C-Y, Guo SL, Jiang C, Gippel CJ (2015) Non-stationary annual maximum flood frequency analysis using the norming constants method to consider non-stationarity in the annual daily flow series. Water Resour Manage 29(10):3615-3633. https://doi.org/10.1007/s11269-015-1019-6 
Xu Y, Zhang X, Hao ZC, Hao FH, Li C (2021) Projections of future meteorological droughts in China under CMIP6 a three-dimensional perspective. Agr Water Manage 252:106849. https://doi.org/10.1016/j.agwat.2021.106849

Yevjevich VM (1967) An objective approach to definitions and investigations of continental hydrologic droughts. J Hydrol 7(3):353. https://doi.org/10.1016/0022-1694(69)90110-3

Zhang Q, Gu XH, Singh VP, Xiao MZ, Chen XH (2015) Evaluation of flood frequency under non-stationarity resulting from climate indices and reservoir indices in the East River basin, China. J Hydrol 527:565-575. https://doi.org/10.1016/j.jhydrol.2015.05.029

Zou L, Xia J, She DX (2018) Analysis of impacts of climate change and human activities on hydrological drought: a case study in the Wei River Basin, China. Water Resour Manage 32(4):1421-1438. https://doi.org/10.1007/s11269-017-1877-1 


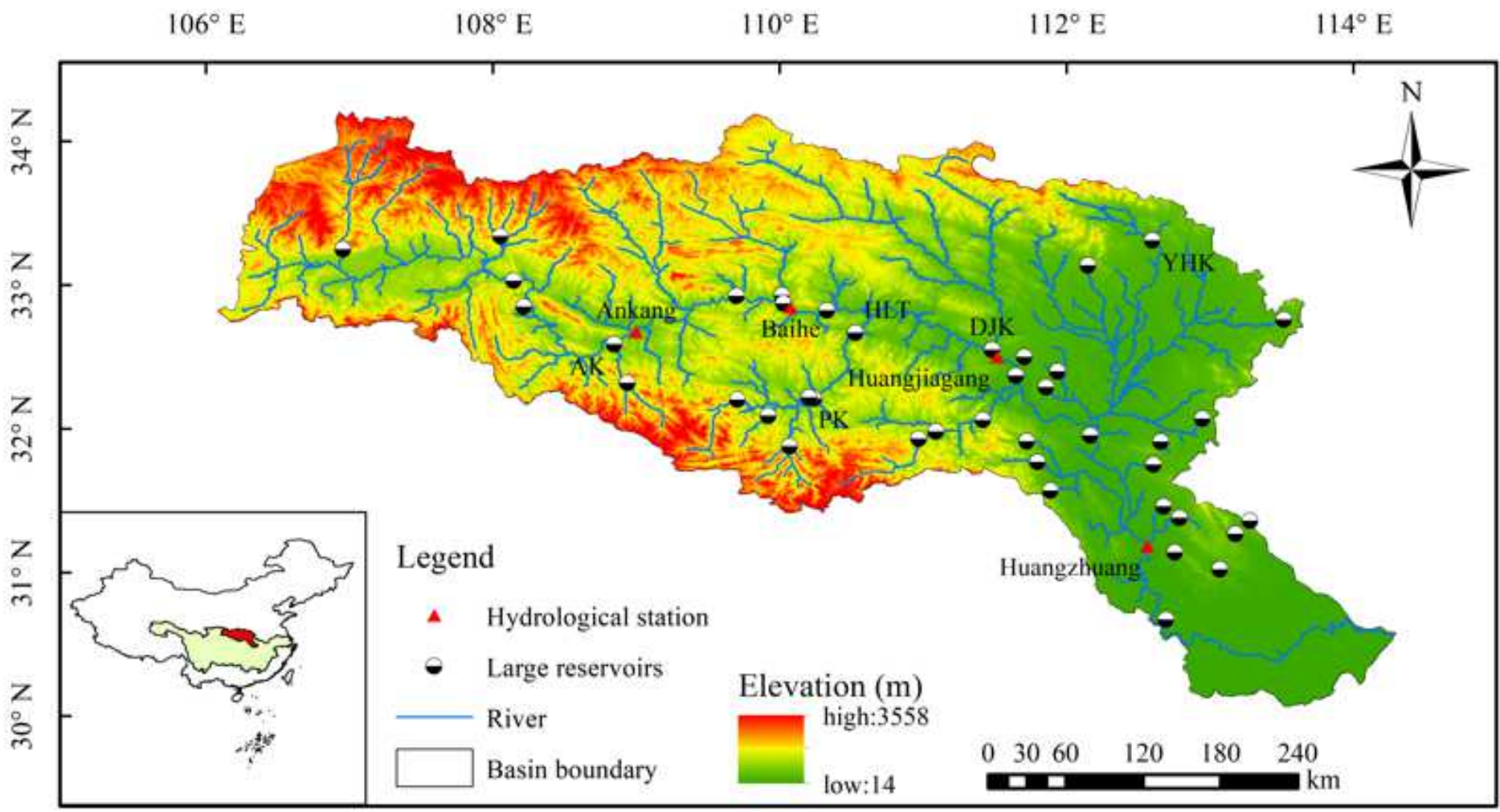

Figure 1

Hydrological stations and large reservoirs in the HRB 

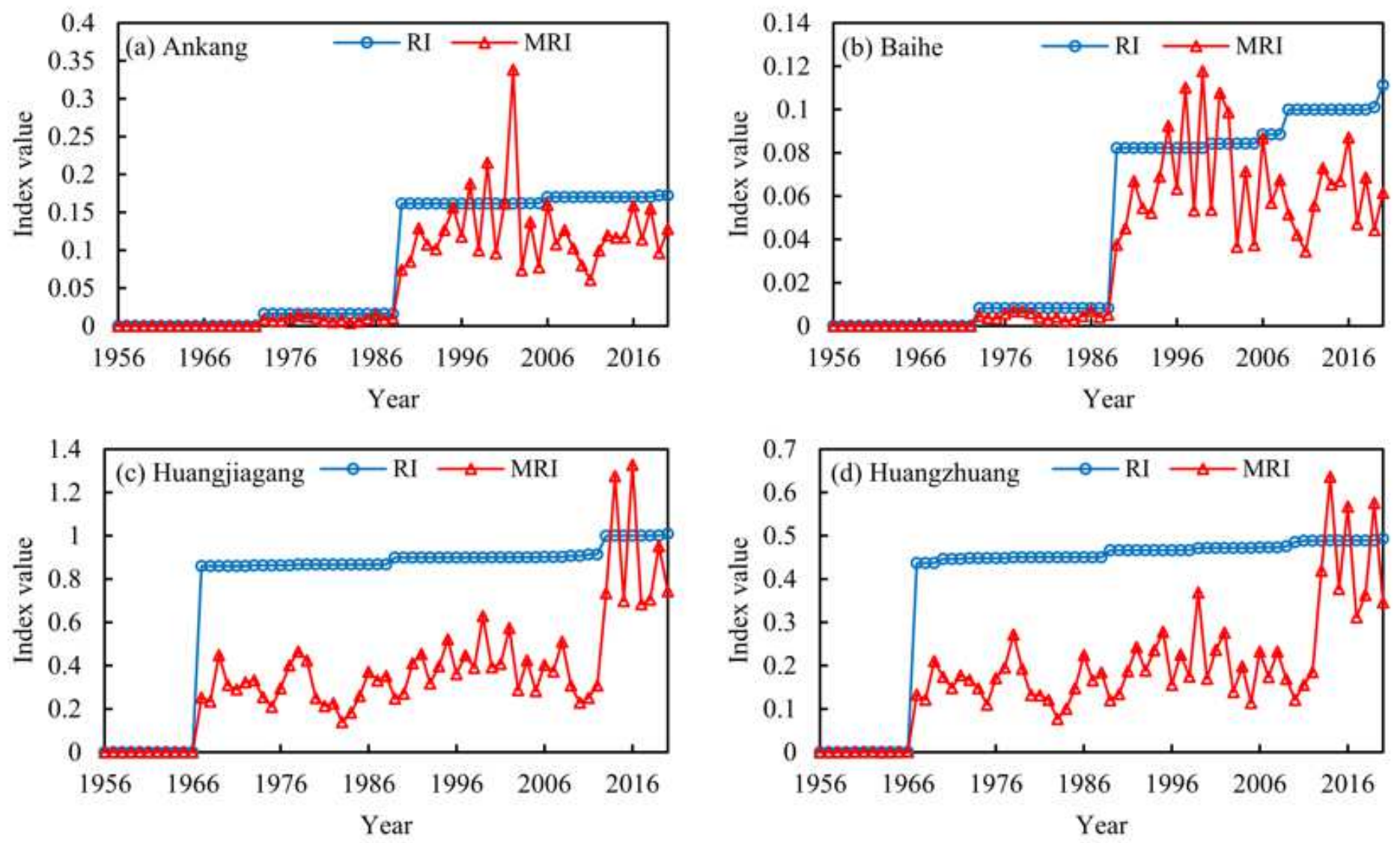

Figure 2

Temporal changes of RI and MRI at four hydrological stations
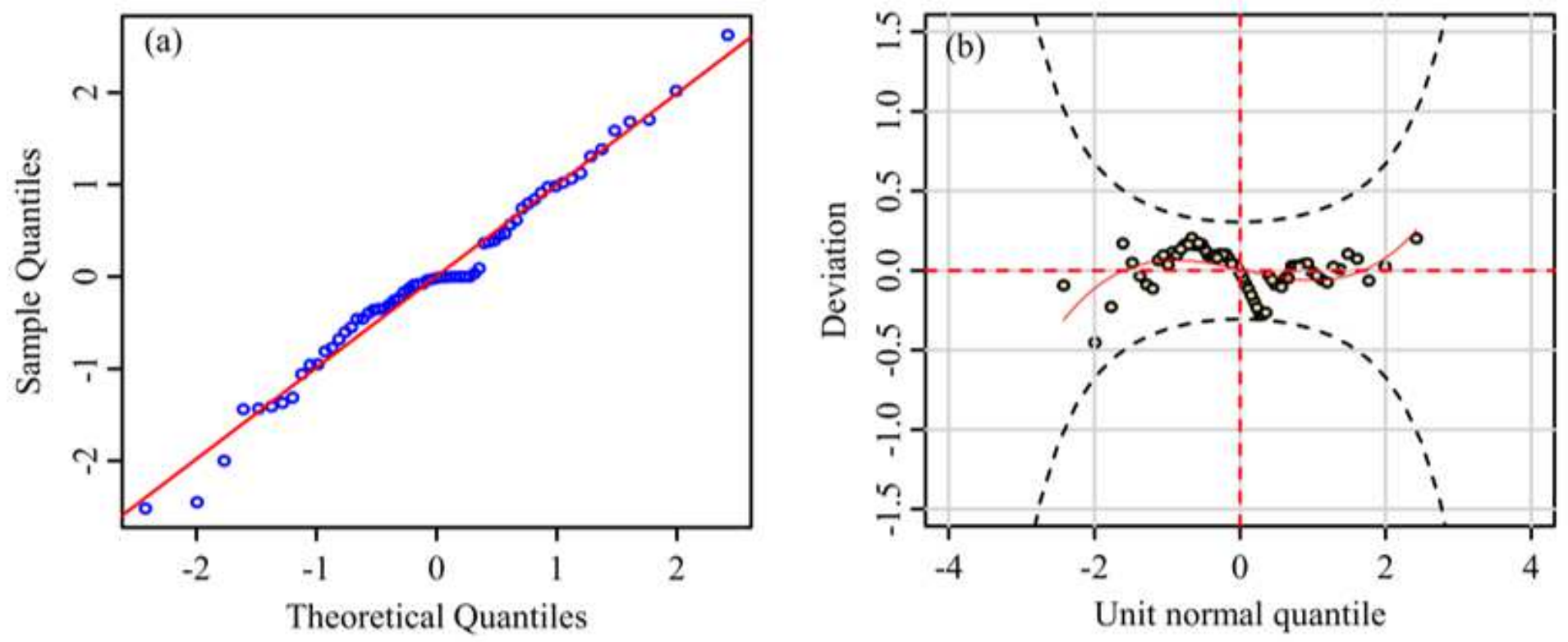

Figure 3 
Normal QQ (a) and residual worm plot (b) from the optimal model for runoff series in December at Huangzhuang station
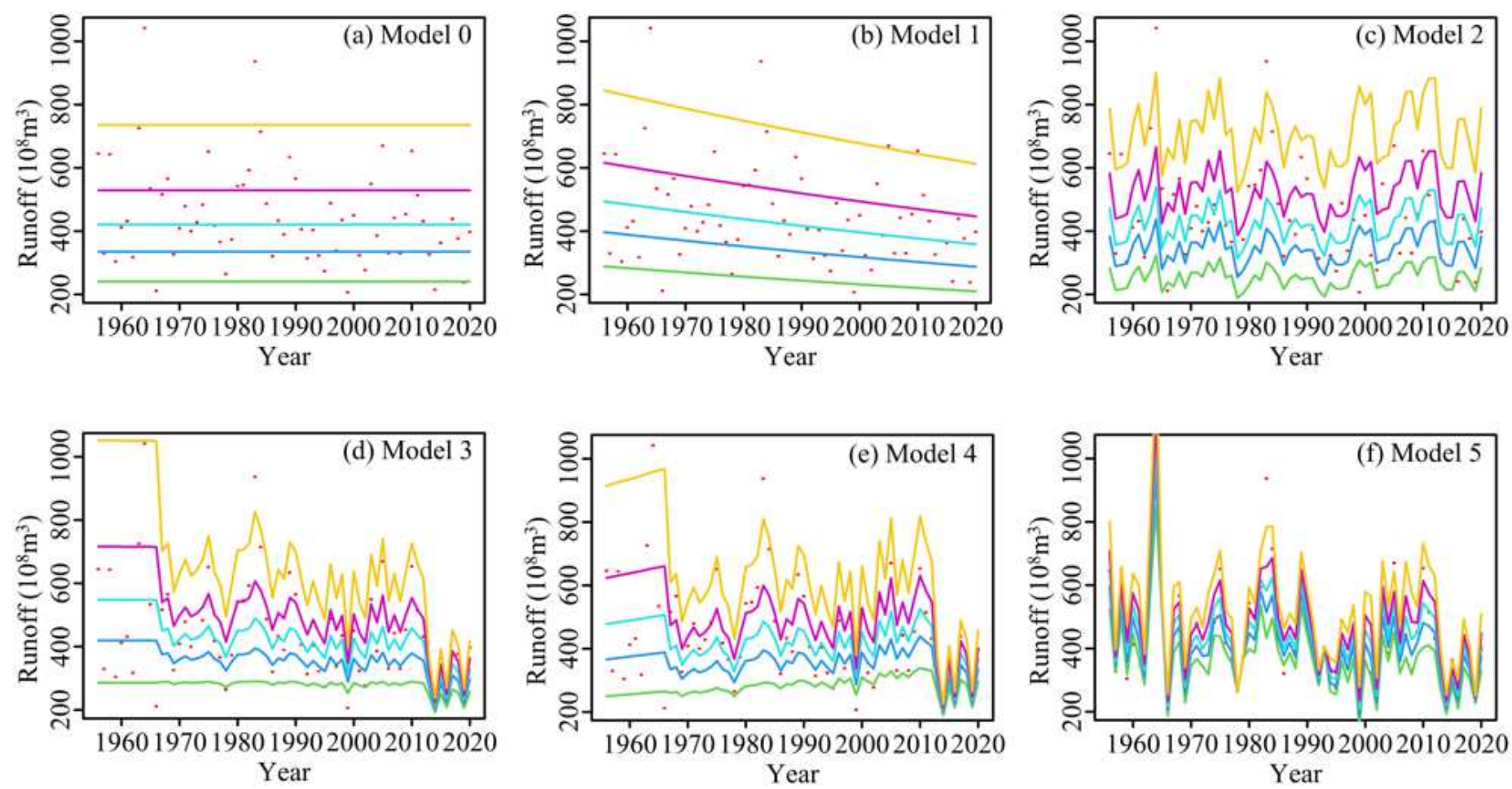

Figure 4

Quantile plot of runoff series for different models in December at Huangzhuang station. The red dots represent observed data. The lines from top to bottom represent the 95th, 75th, 50th, 25th, and 5th quantiles, respectively.

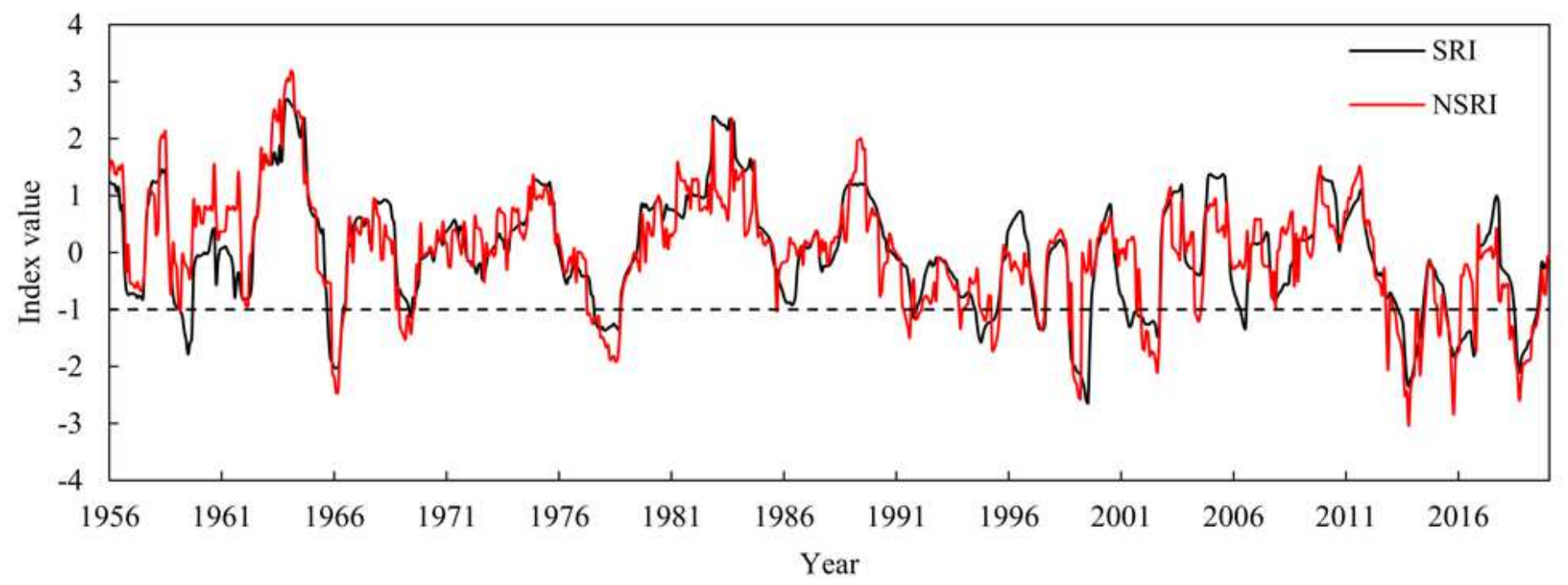

Figure 5

Temporal changes of SRI and NSRI at 12-month time scale of Huangzhuang station from 1956 to 2020 

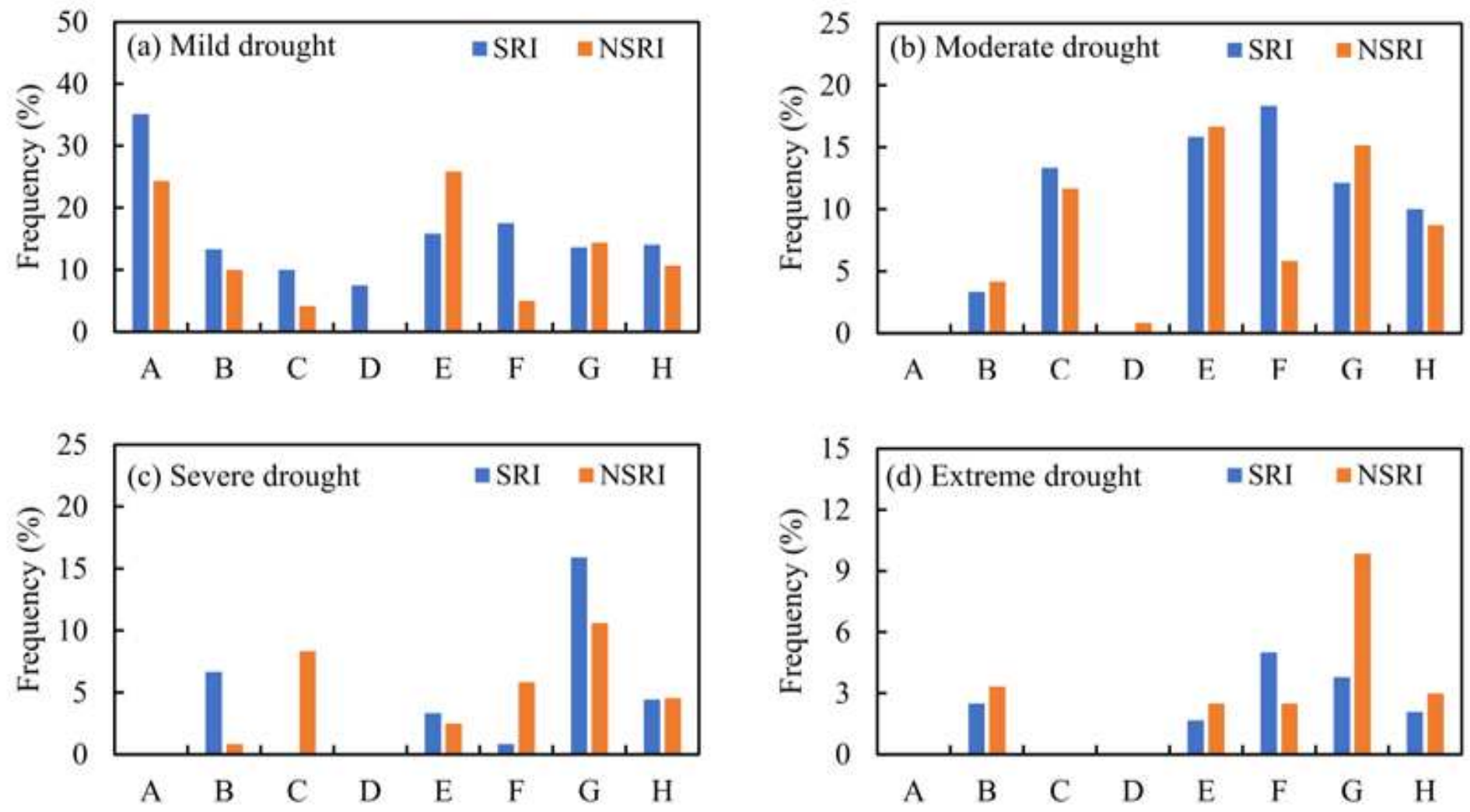

Figure 6

Comparison of drought frequency based on NSRI and SRI at Huangzhuang station under different periods and different drought levels. The A, B, C, D, E, F, G, and H represent the periods of 1956-1959, 1960-1969, 1970-1979, 1980-1989, 1990-1999, 2000-2009, 2010-2020, and 1956-2020, respectively.
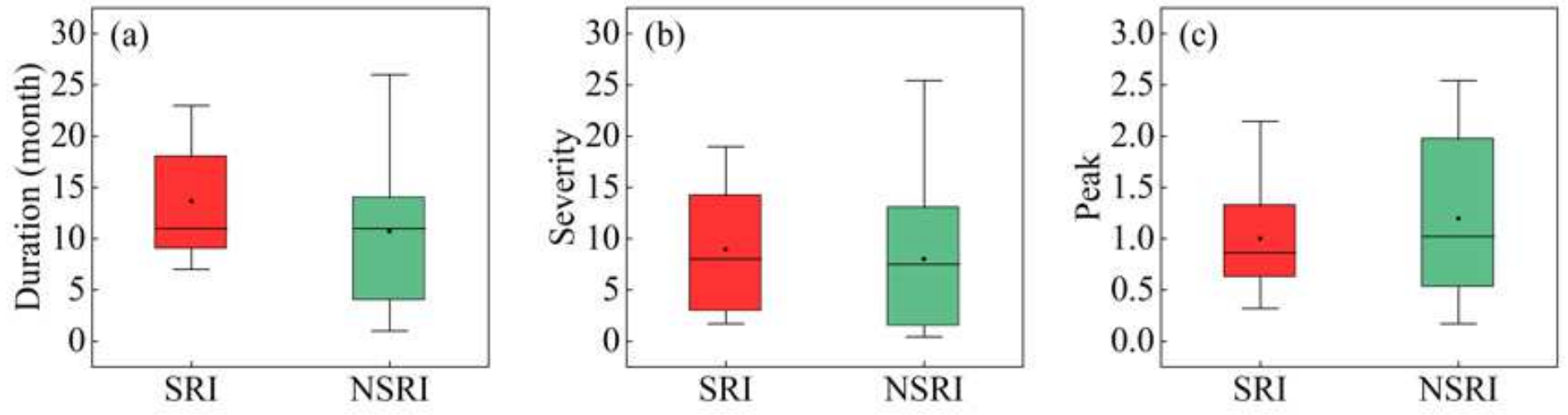

Figure 7

Boxplots of drought properties calculated by NSRI and SRI at Huangzhuang station during 1956-2020 
(a) Ankang

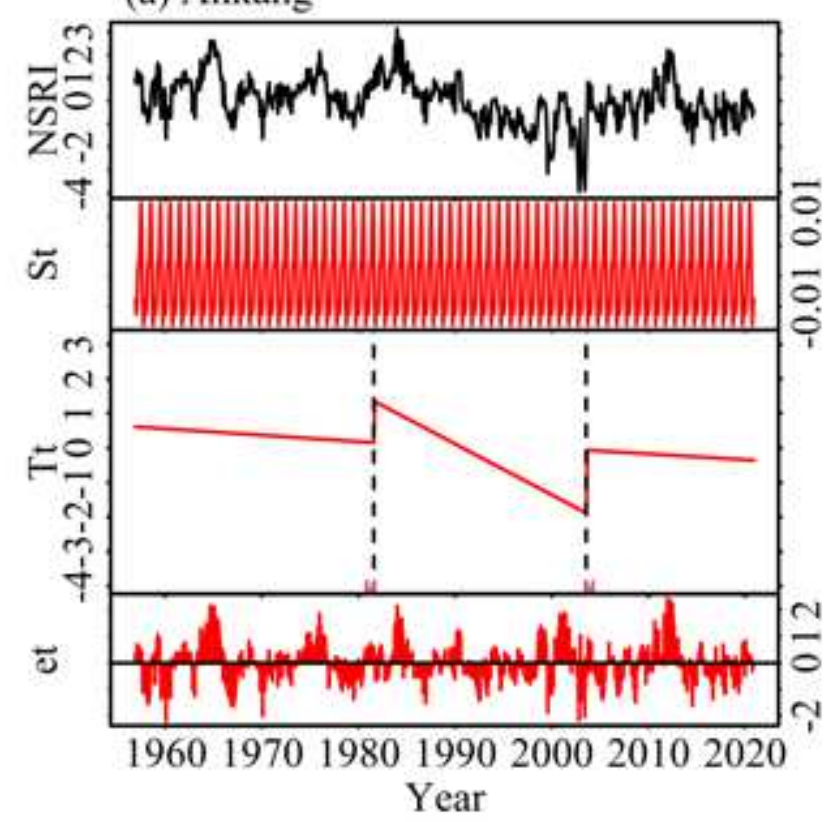

(c) Huangjiagang

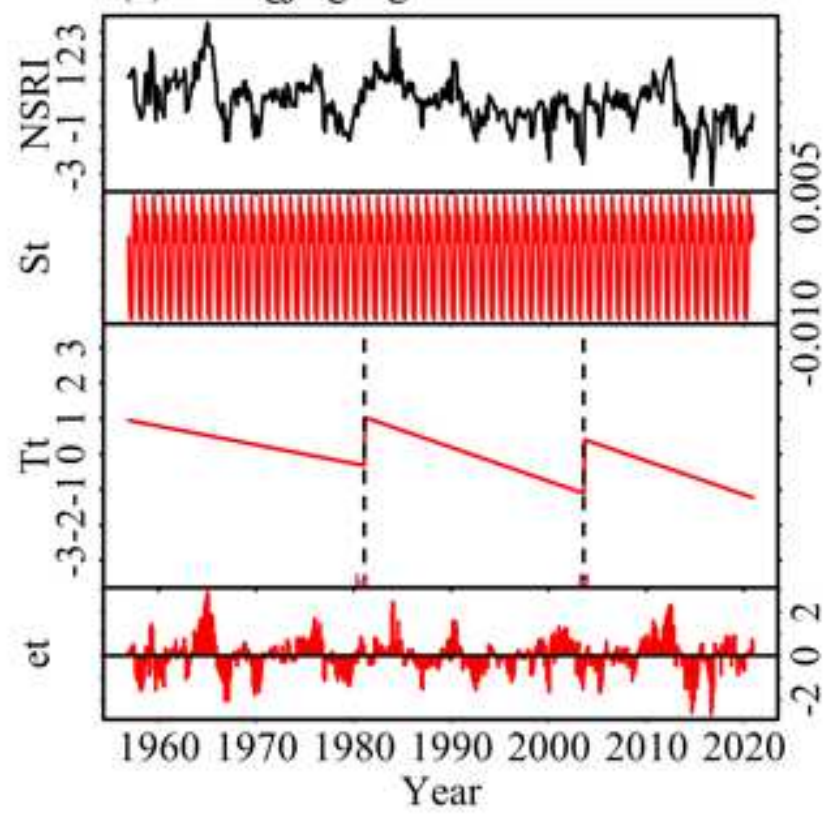

(b) Baihe

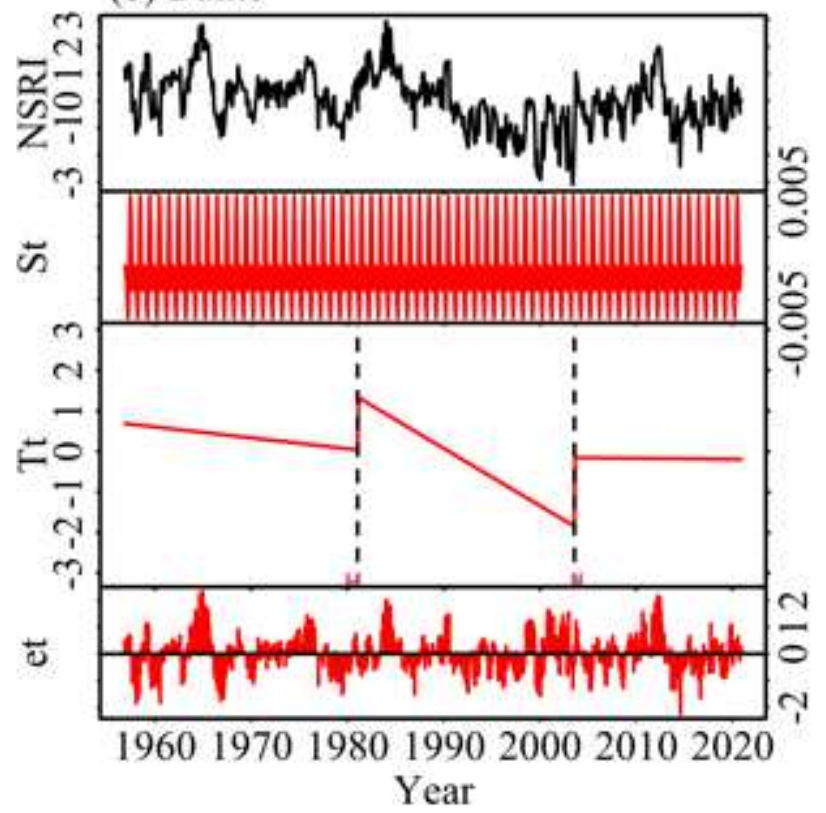

(d) Huangzhuang

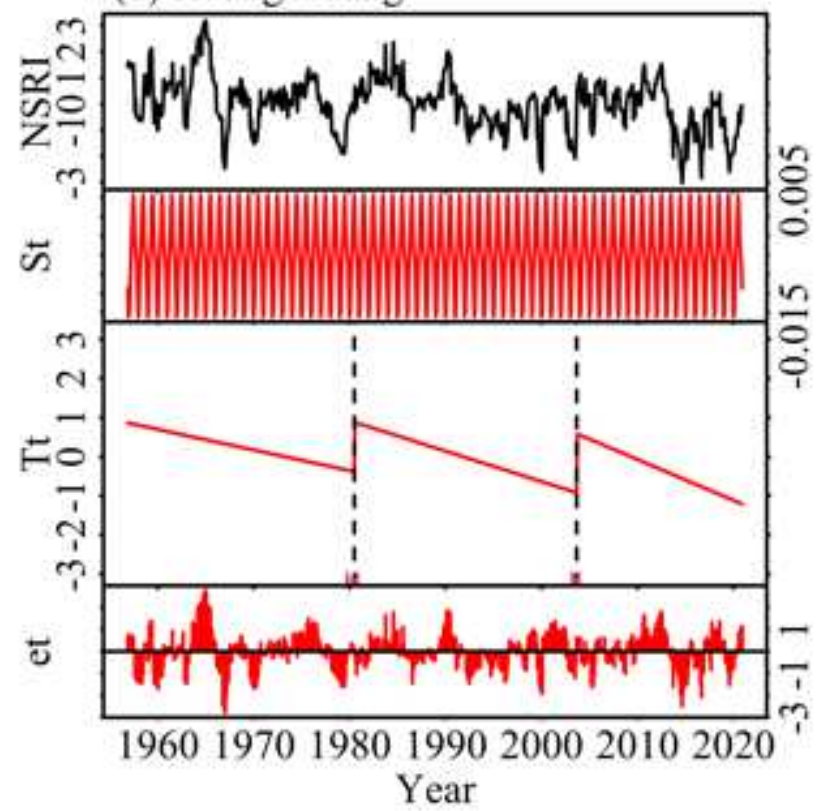

Figure 8

BFAST analysis results of NSRI at four hydrological stations in the HRB 

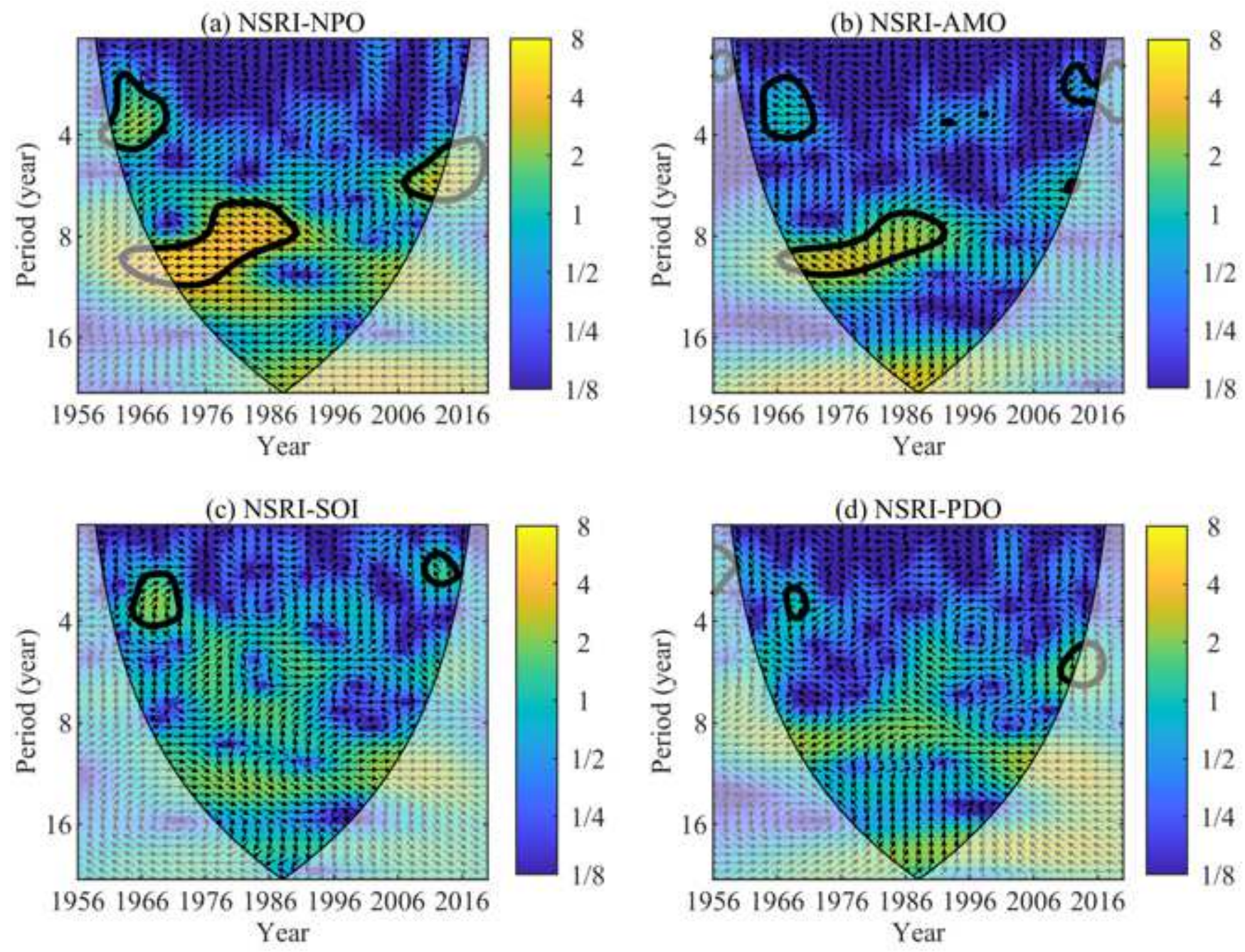

\section{Figure 9}

Cross-wavelet transforms between NSRI and NPO (a), SOI (b), AMO (c), and PDO (d). The 95\% confidence level against red noise is displayed with the black closed solid lines. The relative phase relationship is represented by arrows, with a negative correlation to the left and a positive correlation to the right. 

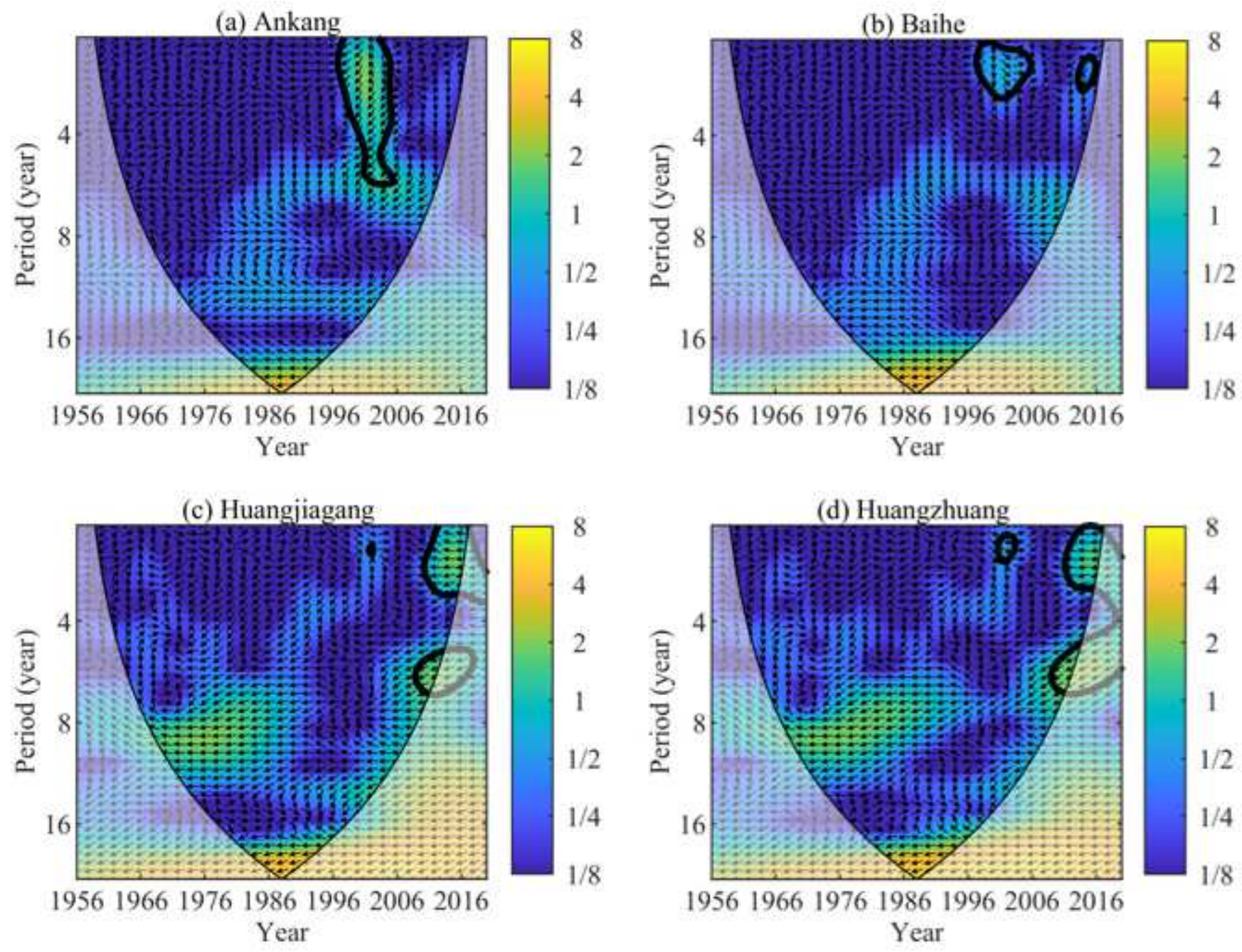

\section{Figure 10}

Cross-wavelet transforms between MRI and NSRI at four hydrological stations. The $95 \%$ confidence level against red noise is displayed with the black closed solid lines. The relative phase relationship is represented by arrows, with a negative correlation to the left and a positive correlation to the right. 